\title{
Diagnose car engine exhaust system damage using bispectral analysis and radial basic function
}

\author{
Piotr Czech ${ }^{1}$ \\ ${ }^{1}$ Faculty of Transport, Silesian University of Technology, Krasinskiego 8 Street, 40-019 Katowice, Poland \\ piotr.czech@polsl.pl
}

\begin{abstract}
Diagnostic systems used in new combustion engines are intended for identifying the location of a element or system which can no longer perform its function assigned by the manufacturer, ensuing to its damage or ordinary wear. Increasing requirements regarding reliability and durability of combustion engines, as well as unfavorable effect on the environment and cost minimization, make that necessary to acquire information on the condition of the engine during its working. In this article is presented an experiment specifying possibilities of leakage diagnosis in car engine exhaust system using artificial neural networks. In the experiment radial basis function (RBF) was used as a neural network classifier. Optimization of the neural classifier was based on the change of $\gamma$ coefficients. The optimization criterion was the minimum testing error. The input data for the classifier was in a form of matrix composed of measures, obtained from vibroacoustic signals and bispectral analysis.
\end{abstract}

Index Terms - diagnostic system, vibration, engine, artificial neural networks.

\section{Introduction}

All over the world, in many scientific institutes, experiments are conducted to monitor various parameters linked with functioning of computerized means of transport [1]-[8]. Development of branches linked with most new technologies does not limit the restrict of basic scientific works which lead to similar measurable effects like increase of safety by increase of the durability of the power transmission system components [9], [10].

Fast and multidirectional development of the diagnosis methodology in recent years caused the rise of new methods applied in the systems of damage location and recognition of the object condition [1]-[3], [5], [8], [11]. The artificial intelligence use in the diagnosis of the state of devices became the object worth consideration. One of the methods belonging to this group is the use of artificial neural networks, which are applied in many new and different fields of science. Neural networks are the refined techniques of modeling, able to represent even the very complex functions with a lot of independent variables.

An artificial neural network consists of parts joined together and called neurons. In order to use the artificial neural network one should equip the network with the knowledge suitable for the task it should perform. This process is called network teaching. In such process each of the neurons should get the teaching data, and the better the quality of the data the better the later effects achieved as a result of the neural network functioning [11]-[13].

In vibroacustic diagnostics are cases, when spectrum of signal power, time-frequency distributions and correlation analysis does not allow for changes identification in non stationary signals. Examples of those variabilities are phase changes. In that case useful can be higher row moments and cumulants and their spectrum [1], [11], [14].

For signals of normal instantaneous values distributions, all cumulant spectrums of higher rows are equal zero. Registered during the diagnostic researches non stationary vibroacustic signals have normal resolutions different than Gaussian distribution.

Low-energy changes of a modulating character accompanying the early stages of elements dysfunction in power transmission systems are possible to be traced with the use of bispectral analysis.

In the notion of the bispectral analysis, a third-order cumulant is used, described with the dependence:

$$
C_{3}\left(\tau_{1}, \tau_{2}\right)=E\left[x(t) x\left(t+\tau_{1}\right) x\left(t+\tau_{2}\right)\right]
$$

where: $\mathrm{E}[\mathrm{]}$ - expected value.

Higher-order cumulants, known also as semi-invariants are the measures of the size of signal change around its mean value. They also possess the ability to expose the existence of non-linearity in a signal.

The cumulants are linked with statistic moments with the use of the following dependences:

$$
\begin{aligned}
& C_{1}=m_{1} \\
& C_{2}=m_{2}-m_{1}^{2} \\
& C_{3}=m_{3}-3 m_{2} m_{1}+2 m_{1}^{3} \\
& C_{4}=m_{4}-4 m_{3} m_{1}-3 m_{2}^{2}+12 m_{2} m_{1}-6 m_{1}^{4}
\end{aligned}
$$

Therefore, for the process with a zero mean value we can write down:

$$
\begin{aligned}
& C_{1}=0 \\
& C_{2}=m_{2} \\
& C_{3}=m_{3} \\
& C_{4}=m_{4}-3 m_{2}^{2}
\end{aligned}
$$

\footnotetext{
* This work is partially supported by Polish State Committee for Scientific Research in years $2010-2014$ as a research project.
} 
Bispectral is a function of two frequencies defined as transform FFT from third-order cumulant:

$$
B S\left(f_{1}, f_{2}\right)=\int_{-\infty}^{+\infty} \int_{-\infty}^{+\infty} C_{3}\left(\tau_{1}, \tau_{2}\right) e^{-j 2 \pi\left(f_{1} \tau_{1}+f_{2} \tau_{2}\right)} d \tau_{1} d \tau_{2}
$$

\section{The description of experiment}

The experiment aimed changing if is it possible to diagnose possibilities of leakage in car engine exhaust system using artificial neural networks and patterns made on vibroacustic signals and bispectral analysis.

Leakage modeled as a damage of exhaust valve plug.

Object of researches was an internal combustion engine with spark ignition on 1,6 capacity $\left[\mathrm{dm}^{3}\right]$ in Ford Focus car.

During the experiment were registered signals of engine head vibration acceleration near exhaust and intake valve 1st cylinder, exhaust value 4th cylinder and gearbox. Measurement were taken for 3rd, 4th and 5th gear in three engine: $2000 \mathrm{rpm}, 3000 \mathrm{rpm}, 4000 \mathrm{rpm}$.

To build damage descriptors for artificial neural networks from vibratory signals designated bispectral distributions (Fig. 1).

Diagnostic method adopted in this experiment was based on comparison diagonal matrix of bispectral vectors. Received frequency characteristics brought under selection and extracted three frequency ranges $-1000 \mathrm{~Hz}, 3000 \mathrm{~Hz}, 5000 \mathrm{~Hz}$. Acceptation in that experiment ranges of different widths was aimed researching influence those factor on correctness of diagnostical information. From each spectrum range designated amount which describes character of range amplitude variability. There was used 36 amounts including variability factor, crest factor, clearance factor, shape factor, impulse ratio, skewness, quarter deviation, mean absolute deviation, arithmetic average, geometric mean, harmonic mean, quartiles, central moments, cumulant, energy factor, root mean square, peak to peak value, maksimum, minimum, variance, percent variability factor. Vector consisting determined measure in each selected pieces of resolution was used like an input for neural classifier. It was created 432 pattern sets ( 36 factors $\mathrm{x} 3$ ways of bispectral matrix diagonal vector selection $\mathrm{x} 4$ places of vibration).

As a neural classifier diagnosing damage occurance condition in engine exhaust system selected neural network RBF (Radial Basic Function). In experiments explored an influence of $\gamma$ factor on classification mistake quantity [10][12].

\section{The results of experiment}

At the first part of the experiment it has tried to build classifiers diagnosing malfunction occurance based on signal registered during relevant rotational speed of engine working at particular gear.

Tables 1-4 presents reached results of classification for the best variation of the $\gamma$ factor value and the benchmark.

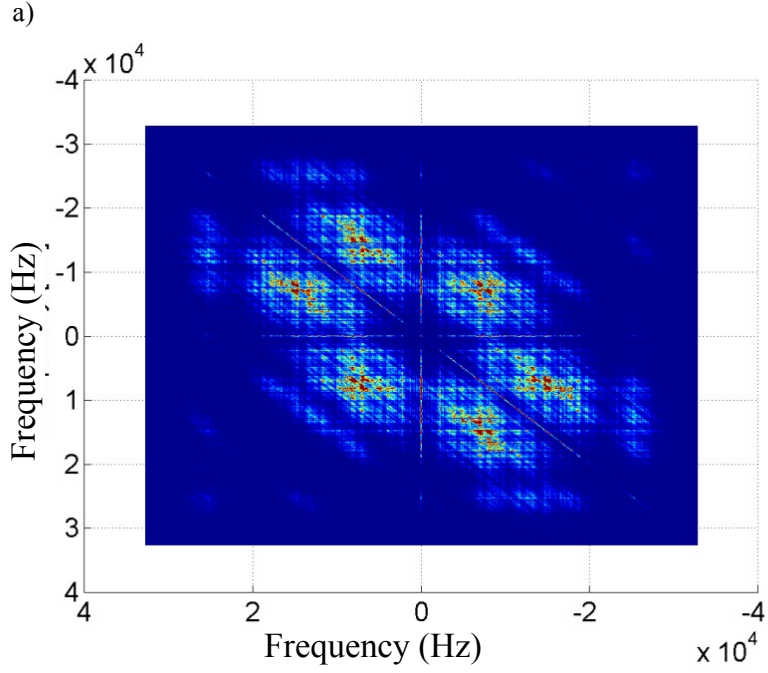

b)

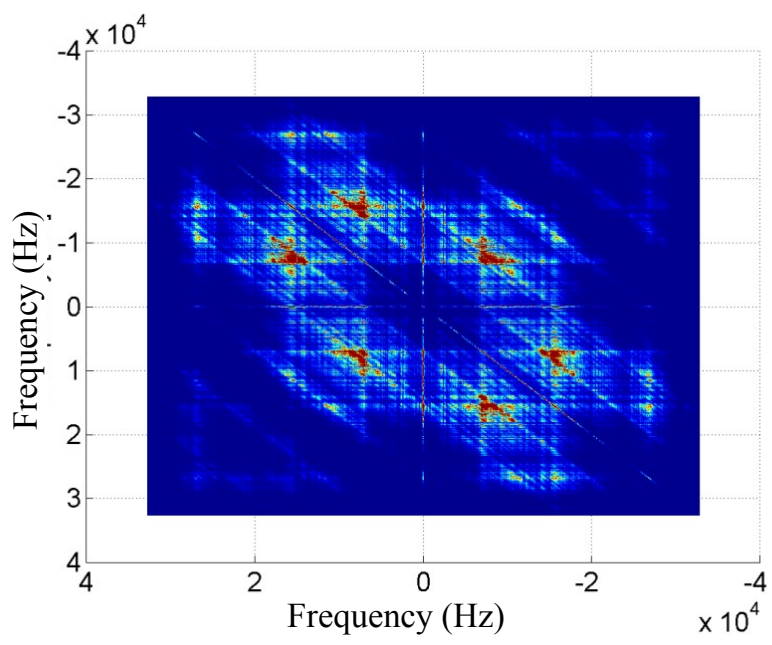

Fig. 1 Bispectral distribution for good engine (a) and for exhaust system malfunction (b)

TABLE 1 Best reached results for signals registered near 1st cylinder exhaust valve

\begin{tabular}{|c|c|c|c|c|}
\hline & \multicolumn{3}{|c|}{ Minimal malfunction value (\%) } \\
\hline & & \multicolumn{2}{|c|}{ gear } & 5 \\
\hline $\begin{array}{c}\text { Engine } \\
\text { rotational } \\
\text { speed (rpm) }\end{array}$ & $\begin{array}{c}\text { Selection } \\
\text { method -wide } \\
\text { spectrum bands } \\
(\mathrm{Hz})\end{array}$ & 3 & 4 & 0 \\
\hline 2000 & 1000 & 0 & 0 & 0 \\
\hline 2000 & 2000 & 6 & 0 & 0 \\
\hline 2000 & 3000 & 4 & 0 & 0 \\
\hline 3000 & 1000 & 0 & 0 & 0 \\
\hline 3000 & 2000 & 0 & 0 & 0 \\
\hline 3000 & 3000 & 6 & 4 & 0 \\
\hline 4000 & 1000 & 0 & 0 & 0 \\
\hline 4000 & 2000 & 2 & 0 & 0 \\
\hline 4000 & 3000 & 0 & 0 & \\
\hline
\end{tabular}


TABLE 2 Best reached results for signals registered near 1st cylinder intake valve

\begin{tabular}{|c|c|c|c|c|}
\hline & & \multicolumn{3}{|c|}{ Minimal malfunction value (\%) } \\
\hline $\begin{array}{c}\text { Engine } \\
\text { rotational } \\
\text { speed (rpm) }\end{array}$ & $\begin{array}{c}\text { Selection } \\
\text { method -wide } \\
\text { spectrum bands } \\
(\mathrm{Hz})\end{array}$ & 3 & 4 & 5 \\
\hline 2000 & 1000 & 0 & 0 & 0 \\
\hline 2000 & 2000 & 6 & 0 & 0 \\
\hline 2000 & 3000 & 4 & 0 & 0 \\
\hline 3000 & 1000 & 0 & 0 & 0 \\
\hline 3000 & 2000 & 0 & 0 & 0 \\
\hline 3000 & 3000 & 6 & 4 & 0 \\
\hline 4000 & 1000 & 0 & 0 & 0 \\
\hline 4000 & 2000 & 2 & 0 & 0 \\
\hline 4000 & 3000 & 0 & 0 & 0 \\
\hline
\end{tabular}

TABLE 3 Best reached results for signals registered near 4th cylinder exhaust valve

\begin{tabular}{|c|c|c|c|c|}
\hline & & \multicolumn{3}{|c|}{ Minimal malfunction value (\%) } \\
\hline $\begin{array}{c}\text { Engine } \\
\text { rotational } \\
\text { speed (rpm) }\end{array}$ & $\begin{array}{c}\text { gear } \\
\text { method -wide } \\
\text { spectrum bands } \\
(\mathrm{Hz})\end{array}$ & 3 & 4 & 5 \\
\hline 2000 & 1000 & 0 & 0 & 0 \\
\hline 2000 & 2000 & 0 & 0 & 0 \\
\hline 2000 & 3000 & 0 & 0 & 0 \\
\hline 3000 & 1000 & 0 & 0 & 0 \\
\hline 3000 & 2000 & 0 & 0 & 0 \\
\hline 3000 & 3000 & 0 & 0 & 0 \\
\hline 4000 & 1000 & 0 & 0 & 0 \\
\hline 4000 & 2000 & 0 & 0 & 0 \\
\hline 4000 & 3000 & 0 & 0 & 0 \\
\hline
\end{tabular}

TABLE 4 Best reached results for signals registered on gearbox

\begin{tabular}{|c|c|c|c|c|}
\hline & & \multicolumn{3}{|c|}{ Minimal malfunction value (\%) } \\
\hline $\begin{array}{c}\text { Engine } \\
\text { rotational } \\
\text { speed (rpm) }\end{array}$ & $\begin{array}{c}\text { gelection } \\
\text { method -wide } \\
\text { spectrum bands } \\
(\mathrm{Hz})\end{array}$ & 3 & 4 & 5 \\
\hline 2000 & 1000 & 0 & 0 & 0 \\
\hline 2000 & 2000 & 6 & 10 & 6 \\
\hline 2000 & 3000 & 18 & 8 & 10 \\
\hline 3000 & 1000 & 0 & 0 & 0 \\
\hline 3000 & 2000 & 0 & 10 & 0 \\
\hline 3000 & 3000 & 0 & 10 & 0 \\
\hline 4000 & 1000 & 0 & 0 & 0 \\
\hline 4000 & 2000 & 0 & 16 & 0 \\
\hline 4000 & 3000 & 0 & 20 & 0 \\
\hline
\end{tabular}

Because this experiment become a success, the next experiment check the activity of classifiers working on data becoming from vibratory signals of engine working at relevant gear, regardless the rotational speed.

Best reached results compared in tables 5-8.

TABLE 5 Best reached results for signals registered near 1st cylinder exhaust valve

\begin{tabular}{|c|c|c|c|}
\hline & \multicolumn{3}{|c|}{ Minimal malfunction value (\%) } \\
\hline & \multicolumn{3}{|c|}{ gear } \\
\hline $\begin{array}{c}\text { Selection method -wide } \\
\text { spectrum bands (Hz) }\end{array}$ & 3 & 4 & 5 \\
\hline 1000 & 4,67 & 2 & 2 \\
\hline 2000 & 8,67 & 1,33 & 2 \\
\hline 3000 & 12 & 4,67 & 4,67 \\
\hline
\end{tabular}

TABLE 6 Best reached results for signals registered near 1st cylinder intake valve

\begin{tabular}{|c|c|c|c|}
\hline & \multicolumn{3}{|c|}{ Mear } \\
\hline & \multicolumn{3}{|c|}{ ginimal malfunction value (\%) } \\
\hline $\begin{array}{c}\text { Selection method -wide } \\
\text { spectrum bands (Hz) }\end{array}$ & 3 & 4 & 5 \\
\hline 1000 & 0 & 1,33 & 0 \\
\hline 2000 & 0 & 0 & 0 \\
\hline 3000 & 0 & 0 & 0 \\
\hline
\end{tabular}

TABLE 7 Best reached results for signals registered near 4th cylinder exhaust valve

\begin{tabular}{|c|c|c|c|}
\hline & \multicolumn{3}{|c|}{ Minimal malfunction value (\%) } \\
\hline & \multicolumn{3}{|c|}{ gear } \\
\hline $\begin{array}{c}\text { Selection method -wide } \\
\text { spectrum bands (Hz) }\end{array}$ & 3 & 4 & 5 \\
\hline 1000 & 2 & 1,33 & 5,33 \\
\hline 2000 & 0,67 & 0,67 & 4,67 \\
\hline 3000 & 3,33 & 1,33 & 4,67 \\
\hline
\end{tabular}

TABLE 8 Best reached results for signals registered on gearbox

\begin{tabular}{|c|c|c|c|}
\hline & \multicolumn{3}{|c|}{ Minimal malfunction value (\%) } \\
\hline & \multicolumn{3}{|c|}{ gear } \\
\hline $\begin{array}{c}\text { Selection method -wide } \\
\text { spectrum bands (Hz) }\end{array}$ & 3 & 4 & 5 \\
\hline 1000 & 6,67 & 2,67 & 3,33 \\
\hline 2000 & 16 & 19,33 & 13,33 \\
\hline 3000 & 13,33 & 16 & 10 \\
\hline
\end{tabular}

In this part of experiment also reached correct results therefore the next trial was made, The trial relies on building a classifier working regardless rotational speed of engine and selected gear,

Table 9 presents best reached results. 
TABLE 9 Best reached results for signals registered on gearbox

\begin{tabular}{|c|c|c|c|c|}
\hline & \multicolumn{4}{|c|}{ Minimal malfunction value (\%) } \\
\hline $\begin{array}{c}\text { Selection } \\
\text { method -wide } \\
\text { spectrum bands } \\
(\mathrm{Hz})\end{array}$ & $\begin{array}{c}\text { 1st cylinder } \\
\text { exhaust } \\
\text { valve }\end{array}$ & $\begin{array}{c}\text { 1st cylinder } \\
\text { intake valve }\end{array}$ & $\begin{array}{c}\text { 4th cylinder } \\
\text { exhaust valve }\end{array}$ & gearbox \\
\hline 1000 & 6,11 & 3,89 & 6,11 & 11,11 \\
\hline 2000 & 11,11 & 4,44 & 7,78 & 10 \\
\hline 3000 & 12,78 & 7,78 & 9,44 & 9,44 \\
\hline
\end{tabular}

Also in this part of the experiment reached results enabling correct identification of malfunction in car engine exhaust system.

\section{Conclusion}

Obtained results in this experiments presents ability to use vibration signals and neural networks RBF for malfunction diagnosis in exhaust system as a damage of adherence of the valve plug.

Results indicate high dependence classify correctness at adopted measure (Fig. 2) and $\gamma$ factor (Fig. 3), however not high dependence on adopted method of diagonal matrix of bispectral vector partition for ranges. Correct results received regardless on registration vibratory signals place.

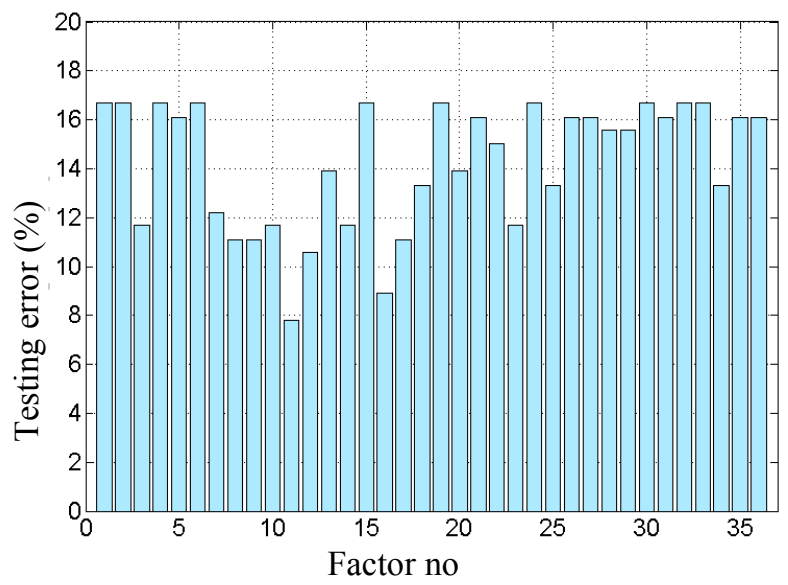

Fig. 2 Exemplary influence of measurement choice on correctness in malfunction classifiers process

\section{Acknowledgment}

The hereby scientific study was financed with funds of Polish State Committee for Scientific Research in years 2010 2014 as a research project.

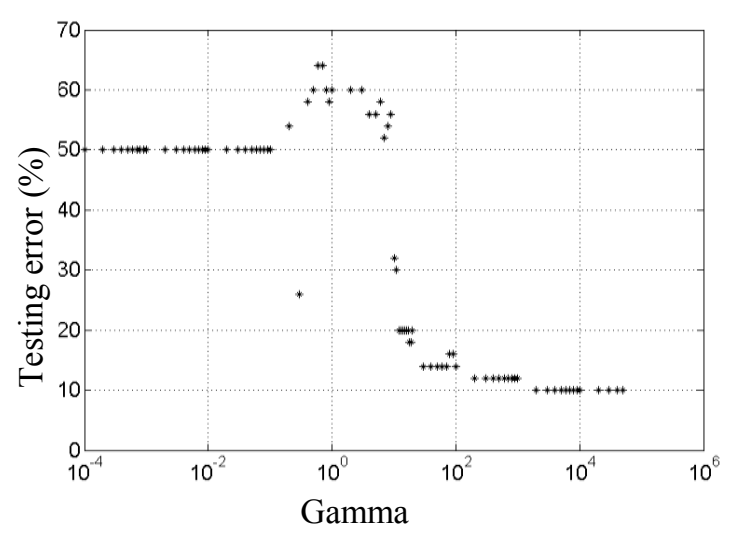

Fig. 3 Exemplary influence of $\gamma$ factor choice on correctness in malfunction classifiers process

\section{References}

[1] P. Czech, B. Łazarz, H. Madej and G. Wojnar, "The use of bispectral analysis and SVM neural networks in the task of gearbox diagnosis", Scientific Journal VISNIK, No 9 (139), 2009, pp. 93-103.

[2] P. Czech and H. Madej, "Application of cepstrum and spectrum histograms of vibration engine body for setting up the clearance model of the piston-cylinder assembly for RBF neural classifier", Eksploatacja $i$ Niezawodność - Maintenance And Reliability, $\mathrm{Nr} 4$, 2011, pp. 15-20.

[3] T. Figlus, "Diagnosing the engine valve clearance, on the basis of the energy changes of the vibratory signal", Maintenance Problems, vol. 1, 2009, pp. 75-84.

[4] R. Grega, J. Homišin, P. Kaššay and J. Krajňák, "The analyse of vibrations after changing shaft coupling in drive belt conveyer", Zeszyty Naukowe. Transport / Politechnika Ślaska, z. 72, 2011, pp. 23-31.

[5] H. Madej and P. Czech, "Discrete wavelet transform and probabilistic neural network in IC engine fault diagnosis", Eksploatacja $i$ Niezawodność - Maintenance And Reliability, $\mathrm{Nr} 4,2010$, pp. 47-54.

[6] J. Młyńczak, "Analysis of intelligent transport systems (ITS) in public transport of upper Silesia", CCIS, vol. 239, 2011, pp. 164-171.

[7] M. Puškár, P. Bigoš and P. Puškárová, "Accurate measurements of output characteristics and detonations of motorbike high-speed racing engine and their optimization at actual atmospheric conditions and combusted mixture composition", Measurement, vol. 45, 2012, pp. 1067-1076.

[8] N. Zuber, H. Ličen and A. Klašnja-Miličević, "Remote online condition monitoring of the bucket wheel excavator SR1300 - a case study", Facta Universitatis, Series: Working and Living Environmental Protection, vol. 1(5), 2008, pp. 25-37.

[9] M. Urbanský, J. Homišin and J. Krajňák, "Analysis of the causes of gaseous medium pressure changes in compression space of pneumatic coupling", Transactions of the Universities of Košice, vol. 2, 2011, pp. $35-40$.

[10] T. Węgrzyn and J. Piwnik, "Low alloy welding with micro-jet cooling", Archives of Metallurgy and Materials, z. 2, t. 57, nr 1, 2012, pp. 539543.

[11] J. Korbicz, J. Kościelny, Z. Kowalczuk and W. Cholewa, Fault diagnosis, Models, Artificial Intelligence, Applications, Berlin: Springer, 2004.

[12] St. Osowski, Neural networks for information processing, Warsaw: UW, 2000.

[13] R. Tadeusiewicz and P. Lula, Introductin to neural networks, Cracow: StatSoft, 2001.

[14].St. Radkowski, "Diagnostics of gears using higher order spectral analysis techniques", 5th International Congress on Sound and Vibration, Adelaide, South Australia, 1997, pp. 1041-1048. 